\title{
Effects of Red Ginseng Extract on Zearalenone Induced Spermatogenesis Impairment in Rat
}

\author{
Eun-Sang Cho ${ }^{1}$, Si-Yun Ryu ${ }^{1}$, Ju-Young Jung ${ }^{1}$, Bae-Keun Park ${ }^{1}$, and Hwa-Young Son ${ }^{2 *}$ \\ ${ }^{1}$ College of Veterinary Medicine, Chungnam National University, Daejeon 305-764, Korea \\ ${ }^{2}$ College of Veterinary Medicine and Graduate School of New Drug Discovery and Development, Chungnam National University, \\ Daejeon 305-764, Korea
}

Zearalenone (ZEA) is a phenolic resorcylic acid lactone compound produced by several species of Fusarium. ZEA has toxic effects in the testes of domestic and laboratory animals. Korean red ginseng (KRG), the steamed root of Panax ginseng Meyer, has multiple pharmacological effects such as vasorelaxation, anti-thrombosis, anti-hypertension, etc. In this study, we investigated the effects of KRG extract on testicular toxicity induced by ZEA. Rats were treated with $300 \mathrm{mg} / \mathrm{kg}$ oral doses of KRG for 4 weeks every other day. The rats were then treated with a single dose of $5 \mathrm{mg} / \mathrm{kg}$ ZEA delivered intraperitoneally, whereas control rats received only doses of the vehicle. As a result, germ cell apoptosis induced by ZEA was decreased by KRG pre-treatment. In addition, Fas and Fas-L expression was reduced in rats that received KRG pre-treatment compared to ones treated with ZEA alone. In conclusion, impaired spermatogenesis resulting from ZEA treatment was prevented by KRG through Fas-Fas L modulating.

Keywords: Panax ginseng, Zearalenone, Korean red ginseng, Apoptosis, Spermatogenesis

\section{INTRODUCTION}

Zearalenone (ZEA) is a phenolic resorcylic acid lactone compound produced by several species of Fusarium, a mold which grows on cereals and grains, such as oats, corn, and hay, exposed to high humidity during storage. ZEA causes alterations to the reproductive tract of laboratory and domestic animals [1]. ZEA is also believed to influence the reproductive system by binding to estrogen receptors [2]. Indeed, exposure to ZEA leads to testicular germ cell depletion through apoptosis $[3,4]$.

Panax ginseng is a herb that has been widely used in traditional eastern Asian medicine for more than 2,000 years. This plant has been considered to be a therapeutic agent that protects against almost all diseases and used in tonics. Among the several kinds of $P$. ginseng products,
Korean red ginseng (KRG) has the most potent pharmacological actions against hypertension, diabetes, cancer, and infirmity [5-7]. Ginseng contains many active components such as ginsenosides, polysaccharides, peptides, fatty acids, and mineral oils [8]. Among the these components, ginsenosides $\mathrm{Rh}_{2}, \mathrm{Rh}_{4}, \mathrm{Rs}_{4}$, and $\mathrm{Rg}_{5}$ that are found only in red ginseng are known to be products derived from the hydrolysis of saponins by processing with heat [9]. In addition, acidic polysccharides have been isolated from KRG and were found to possess immuno-stimulating activities [10] including promoting spleen cell proliferation and nitric oxide production in macrophages [11].

Spontaneous spermatogenic germ cell death is commonly observed during normal spermatogenesis in a

Received 01 Feb. 2011, Revised 09 Mar. 2011, Accepted 09 Mar. 2011

(c) This is an Open Access article distributed under the terms of the Creative Commons Attribution Non-Commercial License (http://creativecommons.org/licenses/by-nc/3.0/) which permits unrestricted non-commercial use, distribution, and reproduction in any medium, provided the original work is properly cited.
"Corresponding author

E-mail: hyson@cnu.ac.kr

Tel: +82-42-821-6787, Fax: +82-42-821-8903 


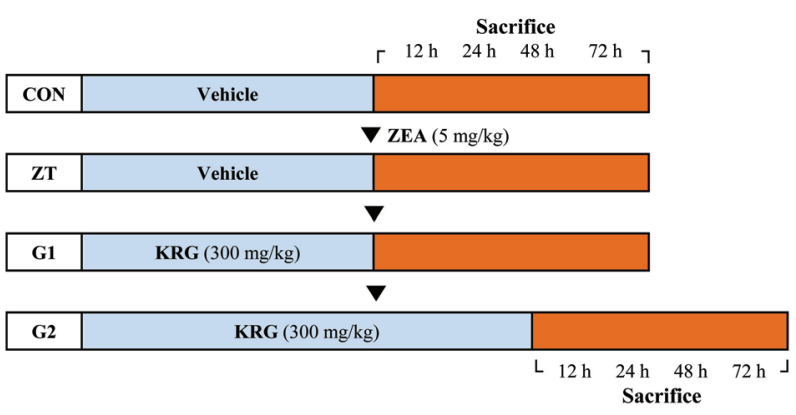

Fig. 1. Experimental protocol. Rats were divided into four groups Korean red ginseng (KRG) extract was administered to the $\mathrm{G} 1$ group for 28 days and for 32 days to the $\mathrm{G} 2$ group every other day. On the 29th day of KRG administration, a single dose of zearalenone (ZEA) was administered intraperitoneally to the ZEA treatment (ZT), G1 and $\mathrm{G} 2$ groups. Rats in the $\mathrm{ZT}$ and $\mathrm{G} 1$ groups were anesthetized with ether and sacrificed at 12, 24, 48, and $72 \mathrm{~h}$ after treatment with ZEA. Control (CON) rats were also sacrificed at these same time points. KRG was administered to the $\mathrm{G} 2$ group for two additional days before the rats were sacrificed ( $n=3$ for each time point).

variety of mammalian species [12]. Germ cell loss is caused by apoptosis controlled by steroid hormones [13], and is increased by testicular toxins [14] or DNA damage from radiation, cytostatic drugs, or genotoxic compounds [15]. Several signaling molecules, such as Fas, TNF- $\alpha$, caspases, p53, members of the Bcl-2 family, and Bax, are activated during germ cell apoptosis [16]. Fas, a transmembrane receptor, localizes to germ cells and is capable of initiating apoptosis when stimulated by receptor crosslinking or binding to its ligand, Fas-L [17]. Fas-L localizes to Sertoli cells in testis, is well known its capacity to induce apoptosis in activated T cells [18]. The Fas signaling cascade was originally characterized as a key mechanism for inducing apoptosis in immune cells, and is known to be the key regulator of germ cell apoptosis in rat and human testis in vitro $[19,20]$. In the present study, we investigated the effects of KRG on ZEA-induced testicular germ cell apoptosis and the underlying mechanisms in a rat model [4].

\section{MATERIALS AND METHODS}

\section{Chemicals}

KRG extract was donated by Korea Ginseng Corporation Central Research Institute (Daejeon, Korea). The extracts were dissolved in distilled water at the final concentration of $30 \mathrm{mg} / \mathrm{mL}$ and kept frozen until use.

\section{Animals and treatments}

Eight-week-old male Sprague-Dawley rats were obtained from Nara Biotech (Seoul, Korea). The rats were housed in polycarbonate cages at $23 \pm 1{ }^{\circ} \mathrm{C}$ in $55 \pm 5 \%$ humidity with a 12-h light/dark cycle. Rodent chow (Jeil Feed Co., Daejeon, Korea) and water were given ad libitum. Rats were randomly divided into four groups: control, ZEA treatment (ZT), and ZEA+KRG groups (G1 and G2; KRG, 300 mg/kg, P.O). Diluted KRG extract was administered every other day to the G1 group for $28 \mathrm{~d}$ and for $32 \mathrm{~d}$ to the $\mathrm{G} 2$ group. Rats received single $5 \mathrm{mg} / \mathrm{kg}$ dose of ZEA (Sigma-Aldrich, St. Louis, MO, USA) or corn oil $(n=3)$ intraperitoneally on the 29th day of KRG treatment. Rats ( $n=3$ at each time point) were anesthetized with ether and then sacrificed 12, 24, 48, and $72 \mathrm{~h}$ after ZEA treatment or two days later in G2 group (Fig. 1). All animal study protocols were approved by the Institutional Animal Ethical Committee of Chungnam National University.

\section{Tissue preparation}

After the animals were sacrificed, testes and epididymides were immediately removed and weighed. The left testis and epididymides were fixed in Bouin's fixative for histopathological and in situ terminal deoxy-nucleotidyl transferase-mediated deoxyuridine triphosphate biotin nick-end labeling (TUNEL) assays. The right testis was instantly frozen in liquid nitrogen and stored at $-70^{\circ} \mathrm{C}$ until the immunoblot assay.

\section{Histological examination}

Fixed tissues were processed by routine histopathological methods. Briefly, tissues were trimmed, embedded in paraffin and sectioned using microtome (Microm, Walldorf, Germany). Sections $4 \mu \mathrm{m}$-thick were stained with H\&E and mounted.

\section{TUNEL assay}

For detect apoptosis in the testes, paraffin-embedded tissue sections were examined using an Apoptag peroxidase in situ apoptosis detection kit (Millipore, Bedford, MA, USA) according to the manufacturer's instructions. TUNEL-positive germ cells were counted in 50 seminiferous tubules from each rats and the average number was calculated.

\section{Immunoblot analysis}

The testes were homogenized in $600 \mu \mathrm{L}$ of RIPA buffer (Sigma-Aldrich), centrifuged at 10,000 xg for $20 \mathrm{~min}$, and the supernatant was collected. Protein concentrations were determined using a BCA kit (Pierce, Rockford, IL, USA) with bovine serum albumin as a standard. Protein samples (30 $\mu \mathrm{g}$ each) were separated by SDS-polyacrylamide gel electrophoresis and transferred to PVDF mem- 
branes (GE Healthcare, Little Chalfont, UK). The blots were processed with a SNAP I.D. ${ }^{\text {TM }}$ Protein Detection System (Millipore). Nonspecific binding was blocked with $0.05 \%$ non-fat milk in TBS-T $(20 \mathrm{mM}$ Tris, $0.5 \mathrm{M}$ $\mathrm{NaCl}$, and $0.1 \%$ Tween $20, \mathrm{pH}$ 7.4). The membranes were first probed with rabbit polyclonal anti-Fas (1:30 dilution; Santa Cruz Biotechnology, Santa Cruz, CA, USA) and rabbit polyclonal anti-Fas-L (1:30 dilution, Santa Cruz Biotechnology) antibodies. The membranes were washed with TBS-T and incubated overnight at $4{ }^{\circ} \mathrm{C}$ with a HRPconjugated goat monoclonal anti-rabbit antibody (1:3000 dilution, Santa Cruz Biotechnology). Immunoreactive bands were visualized with an ECL detection system (GE Healthcare). The relative density of specific bands was analyzed using Image $\mathrm{J}$ analysis software.

\section{Statistical analysis}

All data were analyzed using SPSS ver. 18.0 (SPSS Inc., Chicago, IL, USA) and expressed as the mean $\pm \mathrm{SEM}$. The Mann-Whitney $U$-test was used for statistical analysis and a $p$-value $<0.05$ was considered to be statistically significant.

\section{RESULTS}

\section{Body and organ weights}

ZEA treatment resulted in slightly decreased gains in body weights and relative testicular weights in ZEA treated groups (data not shown). The body weights and relative tissue weights were rapidly recovered during the study.

\section{Pathologic findings}

The testicular seminiferous tubule morphology of rats exposed to ZEA underwent some obvious changes compared to control. Degeneration of germ cells in the seminiferous tubules, characterized by pyknotic nuclei and eosinophilic cytoplasm, were noted in ZEA-treated rats. The majority of affected germ cells were spermatogonia and spermatocytes. These changes were observed mainly after $12 \mathrm{~h}$ and $24 \mathrm{~h}$ of ZEA treatment. Pre- and co-treatment with KRG reduced the degree of these changes (Fig. 2).

\section{TUNEL assay}

Germ cell apoptosis was observed by the TUNEL assay. TUNEL-positive cells were brownish with a round
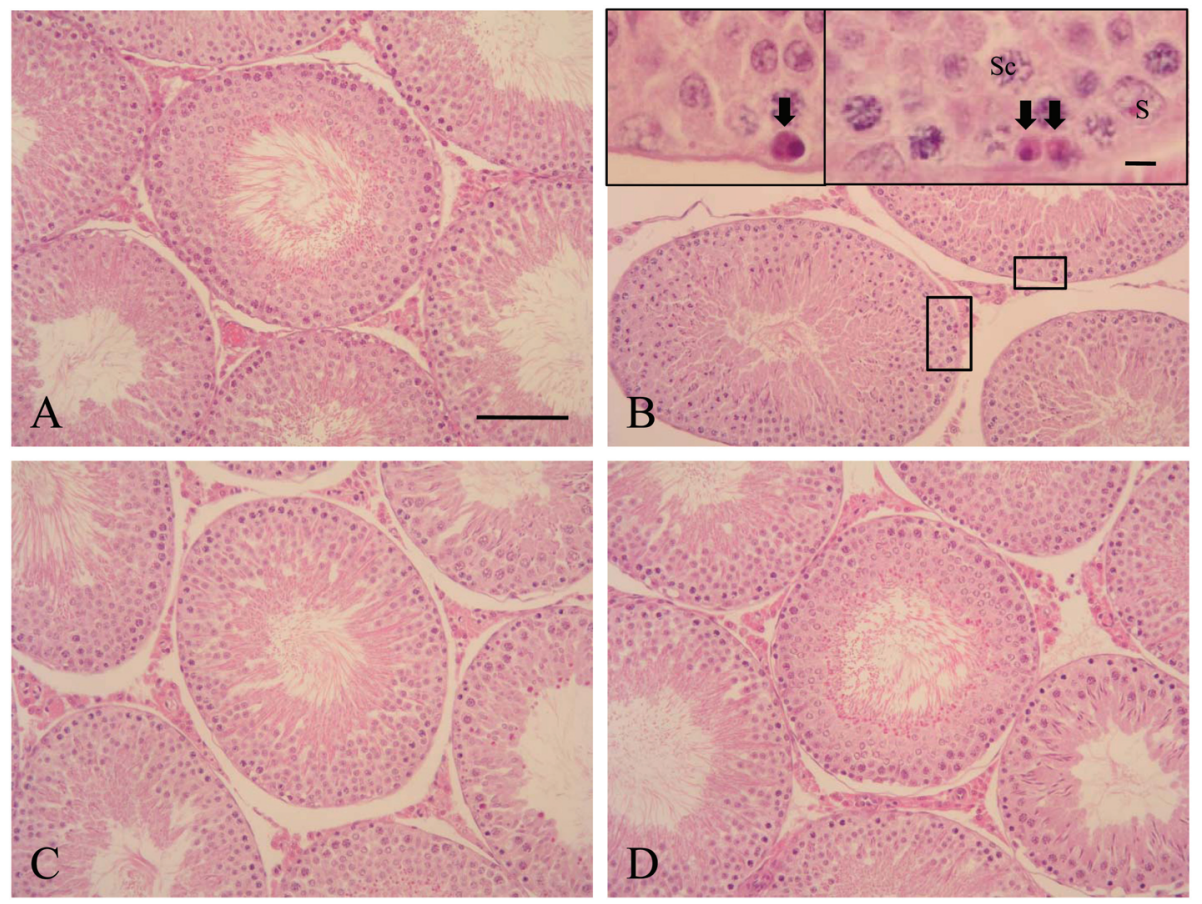

Fig. 2. Histopathological findings of the testes. The cellular structure of the seminiferous tubules was almost normal in appearance for all groups. However, zearalenone (ZEA) treatment induced germ cell degeneration characterized by the appearance of pyknotic nuclei with eosinophilic cytoplasm (arrows). These changes were severe in rats treated with ZEA alone (B) compared to the control (A), G1 (C), and G2 (D) groups. H\&E, x200. Bar=200 $\mu \mathrm{m}$. Sc, spermatocyte; S, Sertoli cell. 

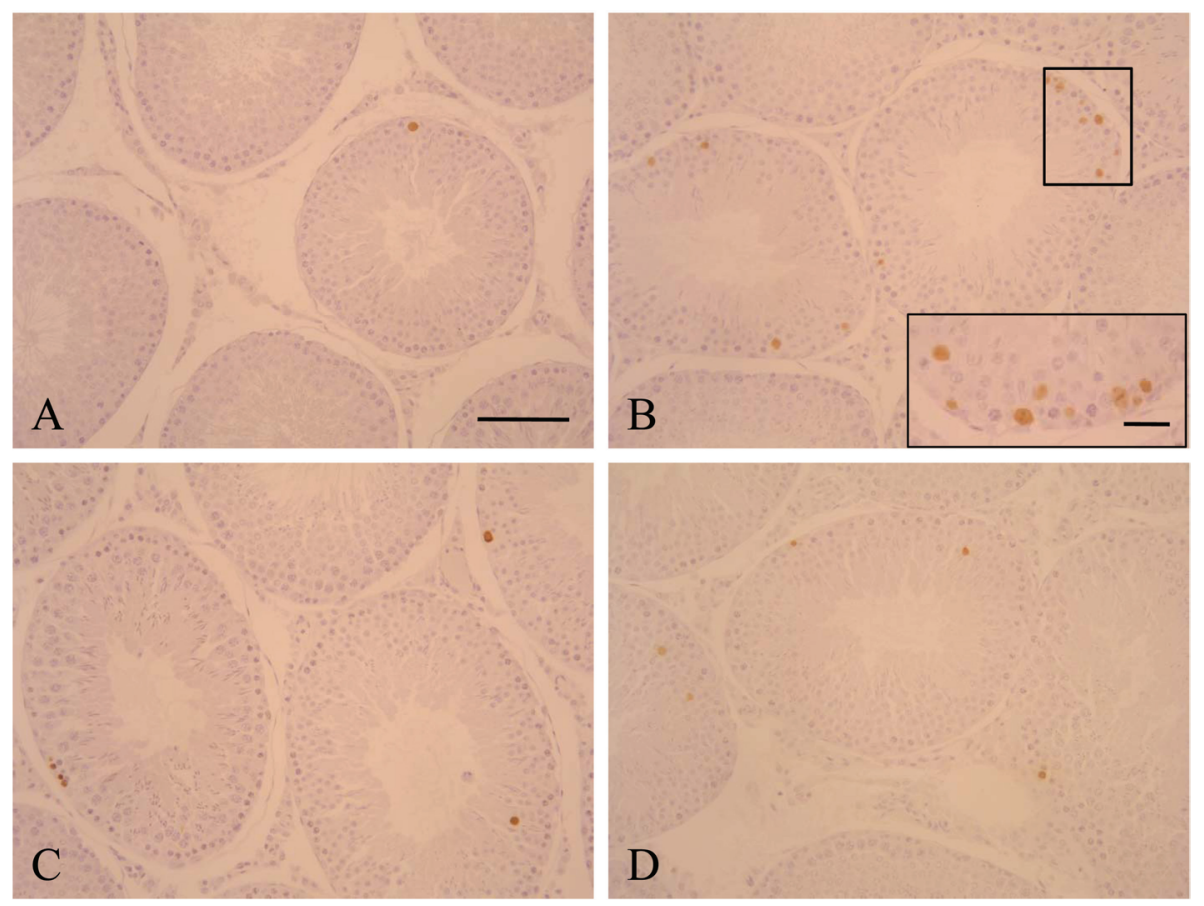

Fig. 3. Terminal deoxy-nucleotidyl transferase-mediated deoxyuridine triphosphate biotin nick-end labeling (TUNEL) assay of the testis. TUNELpositive cells were identified by their brownish staining and were mainly spermatogonia and spermatocytes. The number of TUNEL-positive cells varied among the seminiferous tubules, but was higher in rats treated with zearalenone alone (B) compared to the control (A), $G 1$ (C), and $G 2$ (D) groups. TUNEL, x200. Bar=200 $\mu \mathrm{m}$.

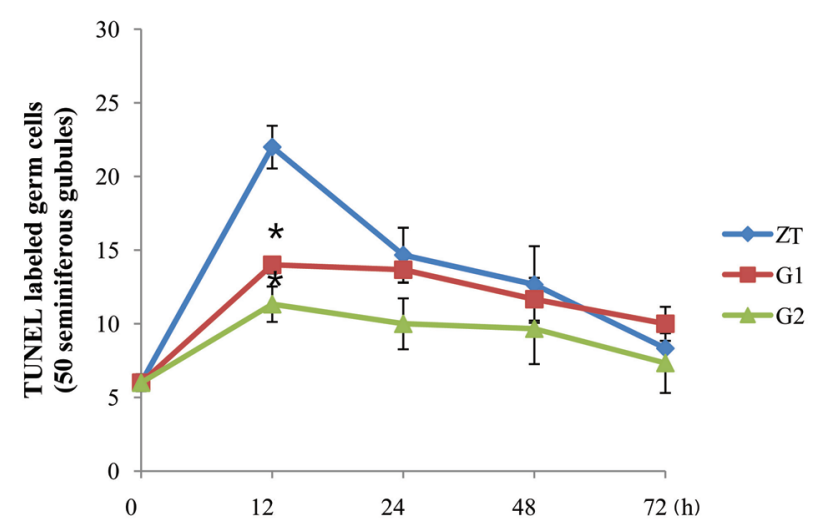

Fig. 4. Quantitative analysis of apoptosis in 50 seminiferous tubules. The number of apoptotic cells peaked after $12 \mathrm{~h}$ of zearalenone treatment and then decreased in a time-dependent manner. The number of terminal deoxy-nucleotidyl transferase-mediated deoxyuridine triphosphate biotin nick-end labeling (TUNEL)-positive cells in the two groups treated with Korean red ginseng (G1, G2) was significantly less than that of the group treated with zearalenone alone (zearalenone treatment [ZT] group) . * $p<0.05$.

shape and detected in the seminiferous tubules. Few apoptotic cells were found in the seminiferous tubules of the control rats. However, numerous apoptotic cells were observed in the seminiferous tubules of ZEA-treated rats. The majority of TUNEL-positive cells were spermatogo- nia and spermatocytes (Fig. 3). The maximum number of apoptotic germ cells were found after $12 \mathrm{~h}$ of ZEA treatment and then gradually decreased after $72 \mathrm{~h}$. Pre- and co-treatment with KRG resulted in a decrease of apoptotic germ cells compared to rats treated with ZEA alone. Cotreatment with $\mathrm{KRG}$ was also more effective for reducing apoptosis induced by ZEA than pre-treatment (Fig. 4).

\section{Immunoblotting}

Various amounts of Fas and Fas-L proteins were detected by Western blotting in the testes of ZEA treated groups from $12 \mathrm{~h}$ to $72 \mathrm{~h}$ after ZEA treatment. Image analyses showed differences among the groups according to the time after ZEA treatment. Fas protein expression was increased in the testis until $12 \mathrm{~h}$ of ZEA treatment after which Fas expression levels were maintained up to $72 \mathrm{~h}$. However, pre- and co-treatment with KRG reduced Fas protein expression that had been increased by ZEA treatment at each time point. Fas protein expression was decreased by pre- and co-treatment with KRG up to $48 \mathrm{~h}$ and was then maintained at level of control rats. Meanwhile, Fas-L expression levels were increased by ZEA treatment up to $24 \mathrm{~h}$ and were then maintained at level of control rats. Co-treatment with KGR abated increases in Fas-L expression in a time-dependent manner compared 

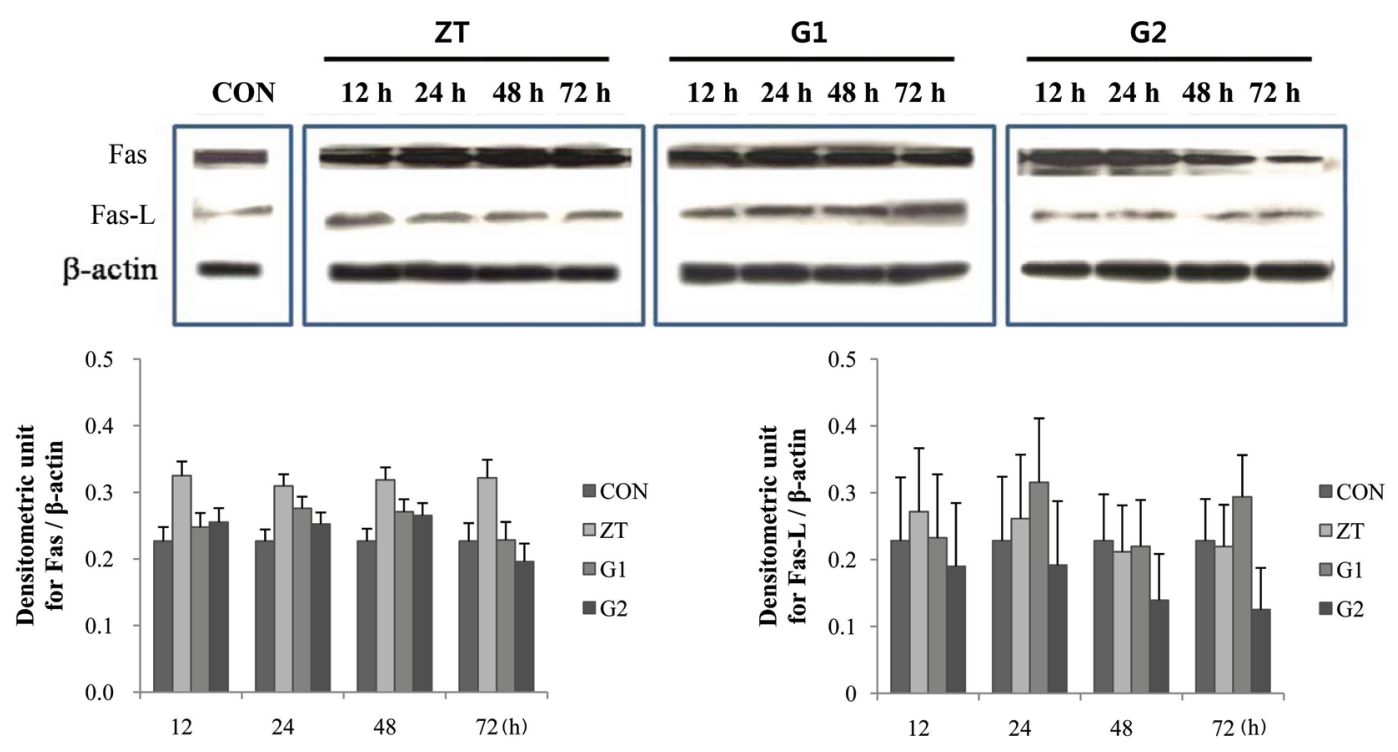

Fig. 5. Effect of Korean red ginseng (KRG) extract on Fas and Fas-L protein expression in the testis. Zearalenone (ZEA) treatment increased Fas protein expression, which was reduced by KRG treatment. Fas-L expression was also increased by ZEA treatment (ZT); however, this was variable in the KRG treatment groups (G1, G2). CON, control.

with to rats treated with ZEA alone. However, Fas-L expression levels varied among rats that were pre-treated with KRG (Fig. 5).

\section{DISCUSSION}

Apoptosis is normally occurs and can be induced by various factors such as exposure to toxic substances [21], hormonal alteration [22], heat exposure [23], or ischemia [24]. We previously found that administering $5 \mathrm{mg} / \mathrm{kg}$ of ZEA to rats induced testicular germ cell apoptosis in a time-dependent manner $[3,4]$. In the present study, we confirmed that ZEA had adverse effects on rat testes including germ cell degeneration and apoptosis. In the histopathological examination, pre- and co-treatment with KGR helped inhibit spermatogenesis impairment and germ cells apoptosis induced by ZEA treatment. These results indicate that KRG exerts protective effects against ZEA-associated testicular toxicity. Furthermore, we showed that expression of Fas and Fas-L was decreased in rats pre- and co-treated with KRG compared to rats treated with ZEA alone. This observation suggests that cell death by ZEA in the testes is related to Fas and Fas-L system activity.

Fas-mediated signaling participates in the initiation of toxicant-induced testicular germ cell apoptosis such as that caused by phthalates [25] and $\beta$-estradiol 3-benzoate [26]. The protective effect of ginseng extract against apoptotic cell death resulting from PCB52 has been evaluated [27]. In addition, Fas-mediated apoptotic cell death is also suppressed in human and murine keratinocyte cells by treatment with ginseng; moreover, the expression of pro-apoptotic genes associated with acute myocardial infarction is down-regulated $[28,29]$. In this study, the number of apoptotic cell as correlated with Fas protein levels. However, Fas-L expression was not matched well with apoptosis. These changes in apoptotic rates may not always correlate with the transcriptional levels [4]. Other proteins such as $\mathrm{p} 21, \mathrm{p} 53$, cytochrome $\mathrm{C}$, and $\mathrm{Bcl}-2$ family members promote germ cell apoptosis in the testis [30-32]. Additional studies are necessary to elucidate the effects of KRG on apoptotic cell death and mechanisms underlying the protective effects of KRG against ZEAinduced germ cell apoptosis.

ZEA is a fusariotoxin that has hematotoxic, immunotoxic, and genotoxic; exposure to this compound also leads to biochemical parameter perturbation in mice $[33,34]$. In addition, ZEA is mutagenic, has reproductive inhibitory effects, and causes oxidative stress $[35,36]$. $P$. ginseng is used widely in traditional Oriental medicine, and has a diverse range of pharmacological and physiological activities [7]. In particular, red ginseng extracts protect against the progression of DNA damage resulting from oxidative stress [37]. The inhibition of germ cell apoptosis and anti-oxidant effects of KRG may be related to the testicular protective effects of this plant. However, 
further studies are needed to better understand the mechanisms underlying the anti-oxidant and anti-apoptotic effects of red ginseng extracts. In conclusion, ZEA increased apoptosis in the testes of the rats and KRG may play a protective role in spermatogenesis impairment induced by ZEA.

\section{ACKNOWLEDGEMENTS}

This work was supported by the 2009 grant from the Korean Society of Ginseng funded by the Korea Ginseng Corporation.

\section{REFERENCES}

1. Mirocha CJ, Christensen CM, Nelson GH. Toxic metabolites produced by fungi implicated in mycotoxicoses. Biotechnol Bioeng 1968;10:469-482.

2. Kuiper GG, Lemmen JG, Carlsson B, Corton JC, Safe SH, van der Saag PT, van der Burg B, Gustafsson JA. Interaction of estrogenic chemicals and phytoestrogens with estrogen receptor beta. Endocrinology 1998;139:42524263.

3. Kim IH, Son HY, Cho SW, Ha CS, Kang BH. Zearalenone induces male germ cell apoptosis in rats. Toxicol Lett 2003;138:185-192.

4. Jee Y, Noh EM, Cho ES, Son HY. Involvement of the Fas and Fas ligand in testicular germ cell apoptosis by zearalenone in rat. J Vet Sci 2010;11:115-119.

5. Jung NP, Jin SH. Studies on the physiological and biochemical effects of Korean ginseng. Korean J Ginseng Sci 1996;20:431-471.

6. Jeon BH, Kim CS, Park KS, Lee JW, Park JB, Kim KJ, Kim SH, Chang SJ, Nam KY. Effect of Korea red ginseng on the blood pressure in conscious hypertensive rats. Gen Pharmacol 2000;35:135-141.

7. Ko RJ. Adulterants in Asian patent medicines. N Engl J Med 1998;339:847.

8. Gillis CN. Panax ginseng pharmacology: a nitric oxide link? Biochem Pharmacol 1997;54:1-8.

9. Nam KY. The comparative understanding between red ginseng and white ginsengs, processed ginseng (Panax ginseng C.A. Meyer). J Ginseng Res 2005;29:1-18.

10. Gao H, Wang F, Lien EJ, Trousdale MD. Immunostimulating polysaccharides from Panax notoginseng. Pharm Res 1996;13:1196-1200.

11. Du XF, Jiang CZ, Wu CF, Won EK, Choung SY. Synergistic immunostimulating activity of pidotimod and red ginseng acidic polysaccharide against cyclophosphamideinduced immunosuppression. Arch Pharm Res 2008;
31:1153-1159.

12. Blanco-Rodríguez J, Martínez-García C. Spontaneous germ cell death in the testis of the adult rat takes the form of apoptosis: re-evaluation of cell types that exhibit the ability to die during spermatogenesis. Cell Prolif 1996;29:13-31.

13. Erkkila K, Henriksen K, Hirvonen V, Rannikko S, Salo J, Parvinen M, Dunkel L. Testosterone regulates apoptosis in adult human seminiferous tubules in vitro. J Clin Endocrinol Metab 1997;82:2314-2321.

14. Richburg JH. The relevance of spontaneous- and chemically-induced alterations in testicular germ cell apoptosis to toxicology. Toxicol Lett 2000;112-113:79-86.

15. Bratton SB, Cohen GM. Apoptotic death sensor: an organelle's alter ego? Trends Pharmacol Sci 2001;22:306315.

16. Schmitz I, Kirchhoff S, Krammer PH. Regulation of death receptor-mediated apoptosis pathways. Int J Biochem Cell Biol 2000;32:1123-1136.

17. Nagata S, Golstein P. The Fas death factor. Science 1995; 267:1449-1456.

18. Xerri L, Devilard E, Hassoun J, Mawas C, Birg F. Fas ligand is not only expressed in immune privileged human organs but is also coexpressed with Fas in various epithelial tissues. Mol Pathol 1997;50:87-91.

19. Lee J, Richburg JH, Younkin SC, Boekelheide K. The Fas system is a key regulator of germ cell apoptosis in the testis. Endocrinology 1997;138:2081-2088.

20. Pentikainen V, Erkkila K, Suomalainen L, Parvinen M, Dunkel L. Estradiol acts as a germ cell survival factor in the human testis in vitro. J Clin Endocrinol Metab 2000;85:2057-2067.

21. Blanchard KT, Allard EK, Boekelheide K. Fate of germ cells in 2,5-hexanedione-induced testicular injury. I. Apoptosis is the mechanism of germ cell death. Toxicol Appl Pharmacol 1996;137:141-148.

22. Russell LD, Alger LE, Nequin LG. Hormonal control of pubertal spermatogenesis. Endocrinology 1987;120:16151632.

23. Miraglia SM, Hayashi H. Histomorphometry of immature rat testis after heating. J Morphol 1993;217:65-74.

24. Turner TT, Tung KS, Tomomasa H, Wilson LW. Acute testicular ischemia results in germ cell-specific apoptosis in the rat. Biol Reprod 1997;57:1267-1274.

25. Richburg JH, Nanez A, Gao H. Participation of the Fassignaling system in the initiation of germ cell apoptosis in young rat testes after exposure to mono-(2-ethylhexyl) phthalate. Toxicol Appl Pharmacol 1999;160:271-278.

26. Kim YH, Cho ES, Kim AY, Kim SH, Kim MS, Cho SW, Ryu SY, Jung JY, Son HY. Toxicological effects of perflu- 
orooctanoic acid in rats. Korean J Vet Res 2008;48:347355.

27. Lee JY, Kim JW, Cho SD, Kim YH, Choi KJ, Joo WH, Cho YK, Moon JY. Protective effect of ginseng extract against apoptotic cell death induced by 2,2',5,5'-tetrachlorobiphenyl in neuronal SK-N-MC cells. Life Sci 2004;75:1621-1634.

28. Yin HJ, Zhang Y, Jiang YR. Effect of folium panax quinquefolium saponins on apoptosis of cardiac muscle cells and apoptosis-related gene expression in rats with acute myocardial infarction. Zhongguo Zhong Xi Yi Jie He Za Zhi 2005;25:232-235.

29. Hosono-Nishiyama K, Matsumoto T, Kiyohara H, Nishizawa A, Atsumi T, Yamada H. Suppression of Fasmediated apoptosis of keratinocyte cells by chikusetsusaponins isolated from the roots of Panax japonicus. Planta Med 2006;72:193-198.

30. Li H, Xu L, Dunbar JC, Dhabuwala CB. Role of mitochondrial cytochrome $\mathrm{c}$ in cocaine-induced apoptosis in rat testes. Urology 2003;61:646-650.

31. Lue YH, Hikim AP, Swerdloff RS, Im P, Taing KS, Bui T, Leung A, Wang C. Single exposure to heat induces stage-specific germ cell apoptosis in rats: role of intratesticular testosterone on stage specificity. Endocrinology 1999;140:1709-1717.

32. Moreno A, Figueras A, Lloveras B, Escobedo A, Griera E,
Sierra A, Fabra A. Apoptosis in ductal carcinoma in situ of the breast. Breast J 2001;7:245-248.

33. Abbes S, Ouanes Z, Salah-Abbes JB, Abdel-Wahhab MA, Oueslati R, Bacha H. Preventive role of aluminosilicate clay against induction of micronuclei and chromosome aberrations in bone-marrow cells of Balb/c mice treated with Zearalenone. Mutat Res 2007;631:85-92.

34. Abbes S, Salah-Abbes JB, Ouanes Z, Houas Z, Othman O, Bacha H, Abdel-Wahhab MA, Oueslati R. Preventive role of phyllosilicate clay on the Immunological and Biochemical toxicity of zearalenone in Balb/c mice. Int Immunopharmacol 2006;6:1251-1258.

35. Yang JY, Wang GX, Liu JL, Fan JJ, Cui S. Toxic effects of zearalenone and its derivatives alpha-zearalenol on male reproductive system in mice. Reprod Toxicol 2007;24:381-387.

36. Ben Salah-Abbes J, Abbes S, Abdel-Wahhab MA, Oueslati R. Raphanus sativus extract protects against Zearalenone induced reproductive toxicity, oxidative stress and mutagenic alterations in male Balb/c mice. Toxicon 2009;53:525-533.

37. Choi HJ, Han HS, Park JH, Son JH, Bae JH, Seung TS, Choi C. Antioxidantive, phospholipase A2 inhibiting, and anticancer effect of polyphenol rich fractions from Panax ginseng C. A. Meyer. J Korean Soc Agric Chem Biotechnol 2003;46:251-256. 